\title{
Avaliação Formativa em Sessão Tutorial: Concepções e Dificuldades
}

\author{
Formative Assessment in Tutorial Session: \\ Conceptions and Difficulties
}

Vanessa Teixeira Duque de Oliveira ${ }^{I}$ Nildo Alves Batista

\author{
PALAVRAS-CHAVE \\ - Avaliação Educacional. \\ - Aprendizagem Baseada \\ em Problemas. \\ - Educação Médica. \\ - Estudantes de Medicina.
}

Recebido em: 28/11/2010

Reencaminhado em: 13/11/2011

Aprovado em: 19/08/2012

\begin{abstract}
RESUMO
A proposta deste trabalho é apreender concepções de estudantes e tutores sobre a avaliação formativa nas sessões tutoriais de um currículo PBL, identificando as dificuldades enfrentadas no desenvolvimento dessa prática. Um questionário Likert foi aplicado a 11 tutores e 45 discentes do sétimo período do curso de Medicina da Universidade Estadual de Montes Claros e uma entrevista de aprofundamento foi realizada com a totalidade dos tutores e 20 estudantes. Os entrevistados percebem a proposta formativa da avaliação na sessão tutorial, definindo-a como processual, reflexiva, dialógica, diagnóstica, e enfatizam a possibilidade de feedback como fator motivador e determinante para solucionar as deficiências detectadas e reforçar as potencialidades percebidas. São identificadas dificuldades relacionadas ao desempenho dos docentes, como falta de preparo, ao desempenho dos estudantes (falta de sinceridade, maturidade) e outras decorrentes da inadequação dos critérios utilizados nos instrumentos avaliativos. Os resultados apontam a necessidade de programas de desenvolvimento docente e discente em avaliação, assim como maior compromisso das instituições que utilizam a metodologia Aprendizagem Baseada em Problemas na busca contínua e reflexiva da coerência com os pressupostos pedagógicos estabelecidos pelo currículo.
\end{abstract}

\begin{abstract}
The purpose of this study is to understand conceptions of students and tutors on formative assessment in the tutorial sessions of a PBL curriculum, identifying difficulties in the development of evaluation practice. Likert questionnaire was administered to 11 tutors and 45 students of seventh period of medical school at State University of Montes Claros and depth interview conducted with all the tutors and 20 students. Respondents perceived the proposed formative assessment in the tutorial session, defining it as procedural, reflective, dialogical, diagnostic, emphasized the possibility of feedback as a motivating factor for determining and addressing the deficiencies and strengthen the perceived potential. Difficulties related to the performance of teachers as a lack of preparation, the performance of students as lack of sincerity, maturity and others arising from the inadequacy of criteria used in evaluating instruments are identified. The results indicate the need for faculty and student development programs and in assessment, as well as greater commitment of institutions using the Problem-Based Learning method in the continuous search and reflective of consistency with the assumptions set by the educational curriculum.
\end{abstract}




\section{INTRODUÇÃO}

Alguns questionamentos sobre a forma de educar e aprender têm determinado que as escolas médicas brasileiras adotem metodologias ativas de ensino como estratégia de ensino-aprendizagem. A necessidade de atender às exigências da Lei de Diretrizes e Bases da Educação — LDB (Lei nº 9.394/1996) e das Leis de Diretrizes Curriculares publicadas em novembro de 2001 foi um importante fator para desencadear essas mudanças em algumas escolas médicas, dentre elas a Universidade Estadual de Montes Claros (Unimontes) ${ }^{1}$.

Nas metodologias ativas, o estudante é o ator principal do processo educacional, que é dinâmico e estimula a construção do conhecimento por meio de uma aprendizagem crítica e autônoma. Considera-se toda a experiência de "vida" trazida pelo aluno e entende-se que ele é mais propenso a aprender quando experimenta uma necessidade de conhecer algo para si mesmo e para sua prática. Apesar de utilizado como sinônimo de metodologia ativa de ensino, o Problem-Based Learning - PBL (Aprendizagem Baseada em Problemas) constitui uma das estratégias ou princípios norteadores de uma proposta pedagógica na qual a aprendizagem se desenvolve em pequenos grupos tutoriais com sete a dez estudantes e o professor passa a ser um mediador (facilitador ou tutor) ${ }^{2}$.

A necessidade de a avaliação da aprendizagem do estudante estar coerente com os pressupostos epistemológicos que norteiam um currículo que utiliza metodologia ativa foi determinante para o uso de práticas avaliativas formativas durante as sessões tutoriais. Troncon ${ }^{3}$ assim define a avaliação formativa:

[...] é aquela realizada, regular e periodicamente, ao longo do processo educacional, para obter dados sobre o progresso conseguido e, deste modo, efetivar a oportuna correção das distorções observadas, preencher as lacunas detectadas, bem como reforçar as conquistas realizadas. Uma importante característica deste tipo de avaliação é o feedback imediato que deve ser fornecido ao estudante, de modo a poder configurar o processo de obtenção de dados como genuína atividade educacional (p. 30).

Nesta proposta de avaliação formativa, é importante que o estudante entenda o contexto do cuidado que o professor tem com ele e esteja disposto a realizar constante reflexão, que se formaliza por meio da autoavaliação. A avaliação dos pares (interpares) surge como um mecanismo para estimular o estudante a ter responsabilidade sobre o aprendizado dos demais participantes do grupo tutorial. Assim, também, todo avaliador precisa ser avaliado - avaliação do tutor pelo estudante ${ }^{4}$
—, introduzindo o conceito democrático de avaliação ${ }^{5}$. Com isso, a avaliação não pode ser um poder apenas do professor, mas deve, sobretudo, representar o cuidado que este cultiva em relação ao direito de aprender do aluno e passar também a observar habilidades relacionais e de comunicação ${ }^{6}$.

Das três propostas avaliativas (autoavaliação, interpares e do tutor), a literatura refere que a avaliação interpares parece ser a mais válida para avaliar habilidades, e a autoavaliação, a de menor acurácia e mais questionada por diversos autores, mas o uso conjunto das três pode melhorar esta efetividade $\mathrm{e}^{7,8}$.

Algumas pesquisas, no entanto, têm demonstrado impasses na realização das avaliações formativas, dentre eles: a atitude preventiva de professores que não se sentem à vontade para fazer críticas; subjetividade; falta de anonimato da avaliação efetuada durante as sessões tutoriais? .

Outra dificuldade percebida é que os tutores, em suas avaliações, tendem a privilegiar a aquisição do conhecimento em detrimento do desenvolvimento de habilidades como a autoaprendizagem, o raciocínio e o compromisso com o aprendizado do grupo ${ }^{10}$. Alguns autores relatam que a dinâmica do tutorial garante um tempo prolongado de convivência entre professores e alunos, mas que apenas isto não é suficiente para garantir uma avaliação efetiva, havendo necessidade de capacitar e treinar os tutores para julgar o desempenho dos estudantes ${ }^{11,12}$.

No estudo de Papinczac et al. ${ }^{13}$, os estudantes consideraram as avaliações irrelevantes, e alguns assumiram atitudes céticas e demonstraram falta de confiança nas avaliações dos colegas. Corrupção do processo devido a amizades, falta de honestidade, falta de habilitação para avaliar a si ou a seus pares e interferência negativa na atmosfera familiar, além do prejuízo à dinâmica do grupo, foram "sentimentos" também relatados.

Este trabalho objetiva levantar e confrontar impasses e barreiras na avaliação formativa nas metodologias ativas, mais especificamente no contexto das sessões tutoriais do PBL, e apreender concepções de tutores e estudantes sobre essa avaliação.

\section{METODOLOGIA}

Esta pesquisa utilizou como contexto o curso médico da Unimontes, que em 2002 iniciou a primeira turma com metodologia PBL. Até o sétimo período, os estudantes discutem situações-problemas em duas sessões tutoriais semanais. Após a discussão de cada problema, é realizada a avaliação formativa, objeto de pesquisa deste trabalho. Cada estudante faz oralmente sua autoavaliação, a avaliação de um colega (interpares), a avaliação do tutor e da atividade desenvolvida. $\mathrm{O}$ tutor também deve avaliar oralmente cada estudante. A avaliação é 
baseada em critérios e utiliza como estratégia a observação sistemática. Uma particularidade da Unimontes é o fato de que, ao final de cada módulo, utilizando os mesmos critérios citados, esta avaliação assume um caráter somativo ao ser convertida em nota.

Foram dois os instrumentos escolhidos para a coleta de dados: questionário fechado e entrevista semiestruturada. $\mathrm{O}$ questionário foi elaborado com uso da escala de Likert, constando de assertivas relacionadas ao assunto, com o objetivo de verificar o nível de concordância do sujeito com uma série de afirmações que expressam algo favorável ou desfavorável em relação a um objeto ${ }^{14}$.

Dois grupos de sujeitos participaram da pesquisa. O primeiro foi formado pela totalidade dos tutores do sétimo período (11 professores), que responderam ao questionário e à entrevista. $\mathrm{O}$ segundo grupo foi formado por 45 estudantes que cursaram o sétimo período no ano de 2008. O número de estudantes que respondeu à entrevista foi determinado pela reincidência de informações ${ }^{15}$.

Os dados obtidos nos questionários foram sistematizados, classificados, tabulados e dispostos em gráficos. Os dados obtidos por meio das entrevistas, após transcrição, foram sistematizados para se submeterem à análise temática, uma das técnicas de análise de conteúdo, valorizando-se os significados presentes nos dados, sua correlação com as questões formuladas e a articulação com o marco teórico adotado na pesquisa ${ }^{16}$.

Para evitar a criação de uma categoria para cada resposta, levando à fragmentação do discurso, confirma-se a permanência dos núcleos direcionadores utilizados na elaboração dos instrumentos: concepção dos discentes e docentes sobre a avaliação na sessão tutorial e dificuldades enfrentadas durante estas práticas avaliativas. Em seguida, unidades de contextos foram sendo separadas do texto, representando a parte mais ampla do conteúdo a ser analisado, que imprime significado e sentido às unidades de registro.

Das análises das entrevistas, com base nos núcleos orientadores, emergiram temáticas que foram agrupadas nas categorias empíricas desta investigação. Os dados quantitativos foram interpretados e analisados junto aos dados qualitativos em busca de inter-relações das informações.

\section{RESULTADOS DA PESQUISA}

\section{Avaliação na Sessão Tutorial: Concepções de Tutores e Estudantes}

Buscando melhor compreensão dos dados que integram essas categorias, reporta-se a Houaiss ${ }^{17}$, que define "concepção" como sendo "a faculdade ou ato de aprender uma ideia ou questão, ou de compreender algo; percepção, modo de ver ou sentir, ponto de vista; entendimento, noção, maneira subjetiva de ver e entender o mundo" (p. 784), apresentando-se muito mais abrangente do que o simplesmente conceituar.

Uma pequena parte dos entrevistados vincula essa avaliação a uma nota que pode ser usada como mecanismo de poder ou repressão por parte do professor, traduzindo uma visão tradicional da avaliação: “Eu acho também que não deveria dar nota apenas no final do módulo e sim a cada sessão [...] o tutor tem 20 pontos para avaliar o estudante, isso acaba funcionando como um mecanismo repressor durante as avaliações".

Entretanto, a grande maioria dos entrevistados refere que não houve apenas a implantação de um novo sistema avaliativo nas sessões tutoriais do curso de Medicina da Unimontes, mas um entendimento, por parte dos docentes e discentes, acerca de uma nova concepção do avaliar, dado reforçado quando aparecem em outras falas conceitos que refletem uma visão inovadora de avaliação. Como primeiro exemplo desses conceitos, surge a avaliação realizada por triangulação, definida pelos estudantes como a possibilidade de confrontar, em um mesmo momento, visões diferentes de sua atuação, sob o "olhar" do tutor, do colega e de sua própria avaliação.

A avaliação interpares é compreendida como expressão desse momento avaliativo, sendo citada como uma experiência inusitada, surpreendente, que permite desenvolver a percepção e a observação do outro: "[...] é o momento de fazer com que o outro colega perceba que ele está com alguma dificuldade. Fazer com que um colega perceba que pode melhorar".

Tanto tutores como estudantes também conceituam a avaliação na sessão tutorial como reflexiva, possibilitando um pensamento sobre as ações ou atividades realizadas, como possibilidade de diálogo com os demais indivíduos envolvidos (tutores e pares) e como motivadora do processo educacional, sendo vista como um momento que possibilita o incentivo ao estudo e desenvolvimento de habilidades: "[...] eu vejo esse momento como a oportunidade de refletir e melhorar o rendimento do meio do módulo ao final".

A avaliação formativa como característica do processo é identificada, permitindo obter dados ao longo do processo educacional e consistindo em uma avaliação que vai além da simples memorização, do simples adquirir conhecimento (Gráficos 1 e 2).

Nesse contexto de uma avaliação formativa, os entrevistados apontam algumas dimensões que a caracterizam: como processual ou contínua, consistindo numa importante estratégia de acompanhamento dos estudantes durante as sessões; como diagnóstica (86,46\% dos estudantes e $81,76 \%$ dos tutores), ao identificar erros e acertos, deficiências e potencialidades, determinando a solução das primeiras ou o reforço das últimas. 


\section{GRÁFICO 1}

Assertiva: "Entendo que a avaliação na sessão tutorial tem finalidade formativa, permitindo obter dados ao longo do processo educacional".

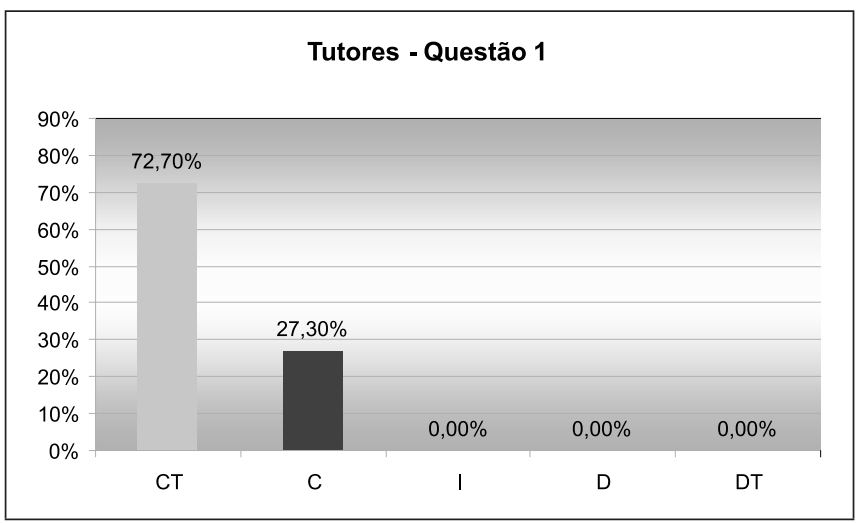

GRÁfico 2

Assertiva: "Entendo que a avaliação na sessão tutorial tem finalidade formativa, permitindo obter dados ao longo do processo educacional".

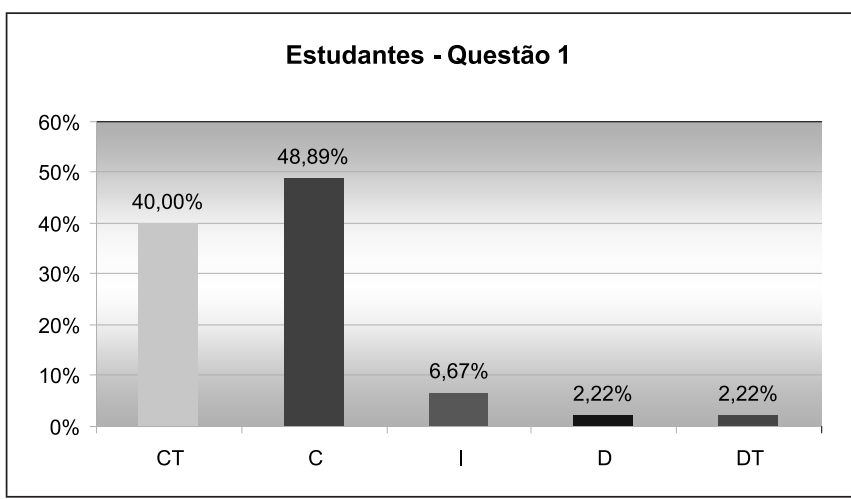

A autoavaliação é destacada como o momento apropriado para realizar uma reflexão que permite ao estudante perceber sua progressão durante o curso. A visão dessa avaliação como estratégia para o desenvolvimento da crítica e da autocrítica é também apontada, assim como a possibilidade de feedback ou estratégia de acompanhamento das atividades e do processo de aprendizagem: "durante a avaliação é que nós vamos perceber se os objetivos propostos pelo problema foram alcançados ou não e se será necessária alguma reformulação para os períodos seguintes".

Alguns entrevistados reconhecem a avaliação como referenciada a critérios que cuidam das habilidades e atitudes que o estudante deve desenvolver ao longo do curso a fim de se tornar um profissional com um perfil que atenda às Diretrizes Curriculares Nacionais para os cursos de Medicina.

\section{Avaliação na Sessão Tutorial: Dificuldades de Tutores e Estudantes}

Os entrevistados identificam um grande número de dificuldades relacionadas ao desempenho dos tutores. A falta de preparo destes é identificada no questionário por $45 \%$ dos tutores e $68,89 \%$ dos estudantes. Os professores reconhecem a necessidade de treinamento ao iniciarem sua atividade docente. Uma tutora lembra o fato de ter-se formado na metodologia tradicional, identificando falta de capacitação em avaliação ainda na graduação. Os professores também percebem a necessidade de discutir a avaliação entre eles como uma forma de trocar experiências e melhorar a atividade avaliativa.

Eu acho que seria essencial que nós tivéssemos momentos de discutir a avaliação, de compartilhar experiências. Às vezes, outro tutor tem um modo melhor de fazer uma avaliação ou viveu experiências boas ou ruins que, se discutidas, teriam melhor resultado para o estudante.

A preferência dos alunos por tutores mais experientes é apontada: "os melhores tutores para avaliar são aqueles que têm experiência de muitas tutorias. $\mathrm{O}$ tutor novo não vai saber que o tutor tem responsabilidade de estar avaliando".

A falta de preparo dos tutores é reforçada, ainda, pela observação de que eles apresentam dificuldade em realizar a avaliação individual do estudante, fazendo apenas uma avaliação geral da sessão; e quando tutores privilegiam apenas os pontos positivos dos estudantes, demonstrando dificuldade em avaliar o aluno com deficiências, ou quando não percebem que alguns estudantes podem "forjar sua participação".

Por outro lado, outros tutores não conseguem propor aos estudantes uma estratégia para melhorar os pontos criticados. Uma tutora encontra maior dificuldade em avaliar o estudante que mantém boa participação, pois teme diminuir a participação dos demais componentes do grupo. Alguns tutores demonstram uma visão ultrapassada da avaliação, realizando avaliações pontuais, sem ênfase no aspecto contínuo e progressivo, e relatando dificuldade no enfrentamento dessa nova forma de avaliar.

Empatias pessoais podem influenciar as avaliações realizadas pelos tutores (confirmado por 63,64\% deles) e são também realçadas pelos estudantes, recompensando ou bonificando determinados alunos.

A falta de compromisso dos tutores é outra dimensão evidenciada nas entrevistas. As falas de alguns estudantes apontam que, em algumas situações, os tutores não valorizam, não reconhecem a importância das avaliações, não se mostram coerentes ou simplesmente não as realizam: 
Teve sessão que, eu sabia, não estava bem, e o professor falava que estava bem. E acabou que isso é ruim. Talvez eu precisasse de mais um incentivo e mais uma atenção [...] o tutor não fala nada do estudante, fala que está tudo bem, mas depois quando vai avaliar ele coloca uma nota que não condiz com que ele falava.

Por outro lado, os estudantes entendem que certas dificuldades dos tutores estão relacionadas a algumas características pessoais, como relutância em enfrentar o outro, fazer e receber críticas ou simplesmente não gostar/sentir prazer em avaliar. Reconhecem, ainda, que algumas dificuldades ligadas à avaliação se devem a aspectos inerentes à avaliação, como a subjetividade, inerente a esse processo.

Os entrevistados apontaram dificuldades relativas ao desempenho dos estudantes nas avaliações. A falta de preparo dos estudantes em relação às avaliações é evidenciada quando os alunos não reconhecem ou valorizam a importância da avaliação; quando percebem a necessidade de maior preparo nos primeiros períodos do curso; quando são incoerentes entre as avaliações, supervalorizando/superestimando suas capacidades durante os momentos avaliativos; e quando priorizam a discussão ou conteúdos em detrimento da avaliação.

[...] tem muita hipocrisia na manifestação de cada acadêmico, que sempre procura amenizar ou supervalorizar a participação de cada um, principalmente quando é interpares. E outras vezes a avaliação do aspecto positivo é quando o acadêmico enche muito a "bola um do outro" e aí vira festa.

Por outro lado, dificuldades decorrentes de timidez, inibição ou simplesmente dificuldade em fazer e receber críticas são associadas às características pessoais do estudante, inerentes aos seres humanos: "[...] ficamos pouco à vontade para realizar esta avaliação. É difícil avaliar a gente mesmo e principalmente um colega. É difícil apontar deficiências frente a frente. [...] é bem chato apontar um defeito do colega, você fica inibido".

Uma dificuldade que pode decorrer tanto de fatores pessoais quanto da falta de preparo é a de avaliar o colega de pior desempenho, conforme identificado pelo tutor?

[...] é interessante observar que os estudantes que tiveram melhor desempenho são os primeiros a serem escolhidos para serem avaliados na interpares, e os que tiveram participação pior ficam para serem escolhidos por último pelos seus pares; isso reflete uma dificuldade para avaliar os colegas de pior desempenho.
A falta de sinceridade é citada pela totalidade dos entrevistados e confirmada pela falta de confiança dos tutores em relação às avaliações realizadas pelos estudantes. O protecionismo entre eles, decorrente de avaliações por afinidades pessoais ou baseadas em amizades, acrescido da busca de benefícios pessoais, também contribui para a falta de sinceridade.

Eu não confio muito no tipo de avaliação que eles fazem. Eu acho que ela não é real. Eu acho que tem um pouco de puxa-saquismo em relação à avaliação que eles fazem do tutor. Eu acho que ela é muito superficial, que ela não corresponde á realidade.

Quarenta por cento dos estudantes relatam apresentar algum "sentimento aversivo", como medo, ansiedade e frustração, durante as avaliações nas sessões tutoriais. Tais "sentimentos" também determinariam dificuldade em manter uma postura sincera e honesta durante as avaliações. O medo de sofrer retaliação do tutor, desencadeando perda de pontos na nota, determina que eles evitem embates com professores e colegas. Além disso, omitem dados por medo de magoar o colega ou comprometê-lo frente ao tutor ao relatarem os erros ou dificuldades apresentados:

[...] ficamos com medo de retaliação por parte do tutor e de gerar conflitos com os colegas [...] medo de falar cara a cara com um tutor que ele não foi bom no seu desempenho [...] medo dele nos tirar nota na avaliação da intranet.

O fato de não acontecer repasse das avaliações que um tutor faz em determinado módulo para o tutor do módulo seguinte é outra dimensão apresentada e que determina dificuldade em avaliar a real progressão do estudante: "ela deveria também ser contínua, mas na verdade ela só é contínua durante um módulo, essa avaliação não é repassada para o tutor seguinte para dar continuidade ao processo".

Eles observam, ainda, a inexistência de uma retroalimentação efetiva. Quando ela é feita, nem sempre resulta em melhorias para os módulos e atividades.

[...] conversando com colegas de períodos anteriores, vemos que muitas críticas já foram feitas anteriormente e que não mudou nada. Pelo fato de a própria coordenação não dar importância às avaliações feitas, a gente fica desestimulado.

A falta de maturidade dos estudantes durante essas avaliações é evidenciada pela dificuldade de enfrentar uma nova forma de avaliar, quando os alunos veem como perseguição a crítica elaborada, constatando conflitos, atritos e mesmo brigas durante esse momento. 
Embora conheçam os critérios utilizados nessas avaliações, tutores e estudantes referem que são usados de forma inadequada, pois não receberam da instituição capacitação sobre os critérios nos primeiros períodos. Na maioria das vezes, isto determina que a avaliação aconteça de forma aleatória, que ocorra variação da forma de avaliar de uma turma para outra ou ainda que exista falta de concordância entre as avaliações realizadas pelos tutores e aquelas efetuadas pelos estudantes. A falta de clareza desses critérios, que dificulta sua utilização, é apontada por $60 \%$ dos estudantes e $45 \%$ dos tutores. Na percepção dos estudantes, há grande variação nas avaliações realizadas pelos tutores e estas são monótonas, pois empregam os mesmos critérios do primeiro ao sétimo período: "[...] acho que essa avaliação é sempre do mesmo jeito. Algo monótona e cansativa".

Os entrevistados apontam ainda a impressão de que essas avaliações acontecem de forma muito frequente. Além disso, a ausência de flexibilidade, a obrigatoriedade e o fato de não acontecerem avaliações da abertura do problema surgem como outras dificuldades.

\section{CONCLUSÃO}

Uma visão diferenciada se evidenciou nesta pesquisa, ao se abrirem oportunidades para que os atores envolvidos fizessem uma meta-avaliação do momento avaliativo, informando e refletindo sobre suas concepções e as dificuldades enfrentadas durante o processo.

O primeiro ponto importante da avaliação na sessão tutorial é representado pela proposta formativa evidenciada pelos entrevistados, relacionando-a com características como a necessidade de se desenvolver, de maneira processual e reflexiva, por meio do diálogo entre os envolvidos e confrontando, em um mesmo momento, visões diferentes da sua atuação, permitindo o diagnóstico de deficiências tanto cognitivas quanto de habilidades e atitudes. Os entrevistados enfatizam a possibilidade de feedback durante os momentos avaliativos como fator motivador e determinante para solucionar as deficiências detectadas e reforçar as potencialidades percebidas.

No momento em que a quase totalidade dos sujeitos aborda conceitos referentes a uma avaliação com importante caráter formativo, consolida-se a percepção de que foi implantado um novo processo avaliativo, segundo pressupostos estabelecidos por um currículo que incorpora a metodologia PBL. Além disso, houve um entendimento e uma aceitação acerca desse processo avaliativo implantado nas sessões tutoriais no curso médico, possibilitando que intervenções metodológicas ocorressem no decorrer do período de ensino-aprendizagem, a fim de superar aparentes dificuldades dos estudantes e falhas dos programas de ensino.

Os entrevistados demonstram perceber que a avaliação não deve ser função única e exclusiva do professor ao informarem que utilizam a triangulação, na qual todos os sujeitos envolvidos (docente e discente) realizam a avaliação. Desta forma, os alunos estão assumindo que são responsáveis pela própria aprendizagem, pela aprendizagem do colega e, consequentemente, estabelecem se estão ou não qualificados para progredir no curso. O professor passa a assumir um papel ativo não só na sessão tutorial, mas também na avaliação dos estudantes. Tal fato determina o exercício participativo, democrático e justo da avaliação, com a lógica de que só pode avaliar quem é avaliado, e permite uma clara argumentação ao garantir ao avaliado a possibilidade de se defender, definindo o aspecto dialético ou dialógico do momento avaliativo ${ }^{18,19}$

Essa noção democrática da avaliação reforça a discussão sobre a diferença das práticas tradicionais de avaliação, que objetivam a simples aprovação, reprovação ou certificação do estudante, voltando-se para uma prática avaliativa que objetiva promover a melhoria da realidade educacional por intermédio de funções que visam à recuperação, à orientação e à formação do sujeito. $\mathrm{O}$ compromisso com o aprendizado do outro por meio da avaliação interpares também se insere nesse novo contexto ${ }^{20}$.

Muitas das dificuldades apresentadas se mostram compatíveis com as pesquisas identificadas na literatura internacional em outras instituições de saúde que vivenciam ou vivenciaram a metodologia PBL como estratégia pedagógica. A falta de anonimato, gerando medo e constrangimentos durante essas avaliações, é um exemplo claro disso ${ }^{21,22}$. Outras dificuldades são próprias da Unimontes, como as decorrentes do fato de a avaliação formativa assumir um componente somativo ao final do módulo na intranet, o que acarreta situações desconcertantes e desagradáveis, contribui para a falta de sinceridade e honestidade, e aponta a necessidade de uma revisão dessa situação apresentada pelos tutores e estudantes.

Os resultados apontam a necessidade de maior compromisso das instituições que implantam a metodologia PBL no que se refere a um acompanhamento e contínua reflexão sobre os processos avaliativos implantados nas sessões tutoriais. Isto requer um intenso compromisso da coordenação do curso, dos coordenadores de período e dos envolvidos na elaboração e execução das avaliações, estabelecendo programas de desenvolvimento docente e também discente em avaliação, numa busca contínua e reflexiva, coerente com os pressupostos pedagógicos estabelecidos no currículo. 


\section{REFERÊNCIAS}

1. Universidade Estadual de Montes Claros (UNIMONTES). Projeto Político Pedagógico para o Curso de Medicina. UNIMONTES, 2008. [capturado em: 18 nov. 2008]. Disponível em: <http://www.unimontes.br/>.

2. Mamede S. Aprendizagem baseada em problemas: características, processos e racionalidade. Fortaleza: Hucitec, 2001.

3. Troncon LEA. Avaliação do estudante de medicina. Medicina São Paulo. 1996; 29(4):430-439.

4. Curet MJ, Mennin SP. The effect of longtermvsshorterm tutors on the quality of the tutorial process and student performance. Advances in Health SciencesEducation, 2003; 8(2):2003.

5. Perrenoud P. Avaliação da excelência das aprendizagens entre duas lógica. Porto Alegre: Artmed; 1999.

6. Oliveira GP. Avaliação formativa nos cursos superiores: verificações qualitativas no processo de ensino aprendizagem e a autonomia dos educandos. Revista Ibero-americana de Educacion, 2002 [capturado em: 7 nov. 2007]. Disponível em: http:/ /www.rieoei.org/deloslectores/261Pastre.PDF.

7. Sullivan ME, Hitchcock MA, Dunnington GL. Peer and self assessment during problem-based tutorials. The American Journal of Surgery. 1999; 111(3):266-269.

8. Papinczak T, Young L, Groves M, Haynes M. An analysis of peer, self, and tutor assessment in problem-based learning tutorials. Medical Teacher. 2007; 29(5):122-132.

9. Almeida LS, Tavares J. Conhecer, aprender e avaliar. Porto: Porto Editora; 1998.

10. Sluijsmans DMA, MerrKnboer JJGV, Dochy FJRC. Peer assessment in problem based learning. Studies in Educacional Evaluation. 2011; 27(2):153-173.

11. Dodds AE, Osmond RH, Elliot SL. Assessment in problem based learning: the role of the tutor. Annals of the Academy of Medicine.Singapore. 2001; 30(4):366-370.

12. Eva KW. Assessing tutorial-based assessment. Advances in Health Sciences Education Theory and Practice. 2001; 6(3):243-257.

13. Papinczak T, Young L, Groves M. Peer assessment in problem-based learning: a qualitative study. Advances in Heath Sciences Education Theory and Practice. 2005;12(2):169-186.
14. Pasquali L, org. Teoria e métodos de medida em ciências do comportamento. Brasília: Universidade de Brasília; 1996 [capturado em: 7 nov. 2007]. Disponível em: http:/ / www.dominiopublico.gov.br/download / texto / me002482.pdf.

15. Minayo MCS. O desafio do conhecimento: pesquisa qualitativa em saúde. 8 ed. São Paulo: Hucitec; 2004.

16. Franco MLPB. Pressupostos epistemológicos da avaliação educacional. In: Sousa CP, org. Avaliação do rendimento escolar. 5 ed. Campinas: Papirus; 1995. p.13-26.

17. Houaiss A, Villar MS, Franco FMM. Dicionário da língua portuguesa. Rio de Janeiro: Objetiva; 2001.

18. Demo P. Avaliação sob o olhar propedêutico. 6 ed. Campinas: Papyrus; 2005.

19. Méndez JMA. Avaliar para conhecer examinar para excluir. Porto Alegre: Artemed; 2002.

20. Hoffmann J. Avaliar para promover: as setas do caminho. 27 ed. Porto Alegre: Meditação; 2008.

21. Van Mook WN, Grave WS, Huijssen-Huisman E, Witt-Luth M, Dolmans DH, Muijtjens AM, Schuwirth LW, Van der Vleuten CP. Factors inhibiting assessment of students' professional behaviour in the tutorial group during problem-based learning. Medical Education. 2007; 41(9): 849-856.

22. Hanranhan SJ, Issacs G. Assessing self- and peer-assessment: the students views. Higher education Research and Development. 2001; 20(1):53-70.

\section{CONTRIBUIÇÃO DOS AUTORES}

Vanessa Teixeira Duque de Oliveira e Nildo Alves Batista contribuíram na concepção e desenho do estudo, análise e interpretação dos dados e redação do texto.

\section{CONFLITO DE INTERESSES}

Declarou não haver.

\section{ENDEREÇO PARA CORRESPONDÊNCIA:}

Vanessa Teixeira Duque de Oliveira

End: Av Maria das Dores Barreto, 1080, casa 175, bairro

Ibituruna

Montes Claros - MG

CEP: 39401-035

E-mail: vanessatdo@ibest.com.br 